\title{
Gum yan asing Kaangas giidaay han hll guudang gas ga. I Will Never Again Feel That I Am Less Than: Indigenous Health Care Providers' Perspectives on Ending Racism in Health Care
}

\author{
Madeleine Kétéskwēw Dion Stout, Cornelia (Nel) Wieman, Lisa Bourque Bearskin, Becky C. \\ Palmer, Lauren Brown, Monica Brown, Namaste Marsden
}

A R T I C LE I N F O

Keywords:

Systemic racism

Indigenous-specific racism

Cultural safety

Human rights

Reconciliation

Anti-racism

Indigenous worldview

Conspiracy of silence

Health equity

Health activism

https://doi.org/10.32799/ijih.v16i1.36021
A B S T R A C T

Racism toward Indigenous Peoples continues to permeate the health care system, a reality the authors know all too well in their shared and yet unique personal and professional experiences. Although acknowledging and speaking up against racial injustice is daunting, and is often met with disregard or inaction, the authors contend that this is a necessary undertaking to redress the ongoing harms of colonialism. Correspondingly, those who do speak up must not have their voices silenced. Instead, the perspectives that Indigenous Peoples have regarding their own experiences of racism must be heeded seriously and produce real and tangible solutions. In narrating their own encounters confronting and challenging racism, the authors juxtapose activism and resistance with the preservation of Indigenous Knowledge as a catalyst for propelling the necessary changes forward within health care to end racism. To truly have an impact, all efforts taken to address racism must occur alongside advancing equity of care and human rights for and by Indigenous Peoples at individual, community, and systemic levels. Changes are not needed after more evidence. The time to act is now.

\section{A U T H O R I N F O}

Madeleine Kétéskwēw Dion Stout, Bear Clan, Kehewin First Nation, RN, MA, Honorary Professor, University of British Columbia, Vancouver, British Columbia, Canada; Order of Canada; Honorary Doctorate, University of British Columbia; Honorary Doctorate, Carleton University, Ottawa, Ontario, Canada

Cornelia (Nel) Wieman, Little Grand Rapids First Nation, MD, MSc, FRCPC, Acting Deputy Chief Medical Officer, First Nations Health Authority, Vancouver, British Columbia, Canada; Adjunct Professor, Faculty of Health Sciences, Simon Fraser University, Burnaby, British Columbia, Canada

Lisa Bourque Bearskin, Beaver Lake Cree Nation, PhD, Associate Professor, Canadian Institutes of Health Research Indigenous Health Research Chair in Nursing; Co-chair, Indigenous Health Nursing Committee, School of Nursing, Thompson Rivers University, Kamloops, British Columbia, Canada

Becky C. Palmer, Takaya Wolf Clan (adopted member of First Nations Health Authority family), PhD, RN, CNM, CEC, PCC, FCAN, Chief Nursing Officer, First Nations Health Authority

Lauren Brown, Haida Nation, MA, BSN, Health Director, XaaydaGa Dlaang Society, Skidegate Health Centre, Skidegate, Haida Nation, British Columbia, Canada

Monica Brown, MA, BSW, Health Director, Haida Health Centre, Old Massett, Haida Nation, British Columbia, Canada

Namaste Marsden, Wilp Gamlaxyeltxw, Lax Ganeda (Frog Clan), LLB, BA, Director, Health Economics and Analytics, First Nations Health Authority; Adjunct Professor, Faculty of Health Sciences, Simon Fraser University. Email:

namaste.marsden@fnha.ca

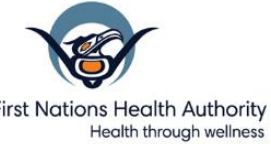




\section{Acknowledgements}

We acknowledge with respect the territories upon which this work was conducted, the host Nations, and the Indigenous partners in the work of the First Nations Health Authority. We also acknowledge our leadership, Chiefs, Board of Directors, and Health Directors. This is dedicated to the many First Nations and Indigenous people who continue to face racism daily, and those who are working toward, and look forward to, safer health care.

\section{Indigenous Knowledge}

Being with nistamosāniwēwin, the birthright of the first born is being there on the face of the earth, waskítaskamik.

Madeleine Kétéskwēw Dion Stout

Opening words, territorial welcomes, and prayers are provided at the beginning of tribal and inter-tribal gatherings where important knowledge, truth, and wisdom are shared, and when ceremony is to occur. In this spirit, and tradition, beloved Cree Knowledge Holder, nurse, teacher, and leader Madeleine Kétéskwēw Dion Stout offers these wise words for all to reflect on as we begin our truth-telling commentary on what is needed to end racism in health care, and what the barriers are. Indigenous creation stories and knowledges affirm the sacredness of all life forms. All our Indigenous relations are sacred, as is all life. Care that is centred in values of sacred life would never allow harms to people, nor would it allow continued harms from racism without redress in the form of justice, compensation, and healing. In her wisdom, Kétéskwēw expresses the need for caring spaces of equity and rights to heath care.

Kétéskwēw insists that we will each have to probe the depths of her words until they are truly understood and can be applied in guiding and generative ways. In her day, she was expected to recall and elucidate the meaning of an orator's wise words on her own, without any prompting or explanations. These words are informed through every trying encounter, through environment, exposure, and experience, as well as colliding intentions and relationships. Kétéskwēw's words underscore how nurses and their allies feel forsaken by an unrequited longing for a world free of racism. These words accentuate the birthright of First People, revered human faces who have carried us to sovereignty, safety, and security from times long ago past.

There is an urgent need for Indigenous knowledges, expertise, and voices to guide the important work of dismantling systemic racism in the health care system. In keeping with traditions of bearing witness, recounting oral history, and upholding the importance of truthtelling, we share our First Nations and Indigenous voices - those of health providers, clinical and community-based-here, speaking to a health system that is failing Indigenous Peoples. Changes are not needed after more evidence. They are needed now. 


\section{Experiencing Racism as an Indigenous Physician}

Dr. Nel Wieman on her personal experiences of racism and witnessing racism in health care, and on the changes needed in professional education, regulation, and culture.

It was my choice to view Joyce Echaquan's horrific final moments on social media that were then captured in the news. Joyce was an Atikamekw woman and mother of seven who died while accessing health care in the Canadian province of Quebec. Her mistreatment and death, which she video recorded and posted online, were the direct result of racism. I felt that I owed it to her to bear witness to her suffering. It seems unlikely that Ms. Echaquan could have known how her life, and her tragic death in a hospital she entered with the hope of receiving care and treatment, would ignite a national conversation on anti-Indigenous racism. I feel a debt of gratitude to her for having the forethought in such a painful and terrifying moment to record her treatment, and as an Indigenous physician, it is with sadness that I know her experience in the health system was not an isolated incident.

As an Indigenous physician with over 20 years of clinical experience, I have witnessed many instances of racist treatment of Indigenous patients, and as a member of the health care workforce, I have experienced racism myself. While the recent release of the In Plain Sight report details widespread systemic racism in the British Columbia (BC) health system, and details many recommendations for action, themes within the report emerge that are relevant nationally and even internationally (BC Ministry of Health, 2020). One such theme is cultural safety training. Cultural safety training for everyone who works in the health system is necessary, but is not a panacea. Ending racism will require a multi-layered approach. In health professionals' education, anti-racism education must be added to the curriculum and embedded in the admissions process and continuing professional development. We need to work toward establishing a "zero tolerance" environment for racism and cultivate a "speak up" culture in the health system so that everyone can be safe while reporting instances of observed racist behavior. Those practitioners who demonstrate racism need to be held accountable by their regulatory bodies. And health organizations need to strengthen their anti-racism activities and policies that would be evaluated through the accreditation process. The ultimate goal of these actions is to make it possible for Indigenous patients to receive culturally safe, equitable health care.

\section{Addressing Systemic Racism as Indigenous Nurses}

Dr. Lisa Bourque Bearskin and Dr. Becky Palmer on the necessity of upsetting the status quo and the courageous personal actions needed to change care culture and environments.

Indigenous nursing professionals are not only bearing witness to the unfolding influence of prolonged harm and genocide against Indigenous Peoples' health and wellness, but also live the day-to-day and difficult realities of dealing with these devastating impacts, as witnessed and experienced in the high-profile cases of Brian Sinclair, Joyce Echaquan, and Silatik Qavvikthree Indigenous people who sought health care in two Canadian provinces and ultimately lost 
their lives because of racist care. Acknowledging colonial-oppressive nursing practices is a first step toward meaningful, lasting, system-wide policy and institutional change.

Nurses and other members of the health care team can no longer be complicit in maintaining colonial processes (Bourque Bearskin, Kennedy, \& Joseph, 2020; Canadian Association of Schools of Nursing, 2020; Symenuk et al., 2020; Thorne, 2019). The facts and the lived experiences of Indigenous Peoples who have been harmed accessing care are a wake-up call for all health care providers to act immediately. Be introspective, take accountability, and act on the uncomfortable realities of systemic racism. Recentre the profession to abandon antiIndigenous racism and nursing structures and policies that cause harm and have served to maintain the status quo. Change begins with caring and the courage to make a difference, as well as the bravery to act. Needed acts of caring go beyond caring for the physical body: Health care professionals must care to understand how white supremacy influences broader historical colonial practices that continue to be harmful, including acts of corporal violence. Caring without action is ineffective, so nurses play a pivotal role in not only creating a climate of change, but also championing a climate of action. Action begins with a critical exploration of one's own positioning and belief systems that embrace cultural safety and humility. It means being inclusive, listening without judgment, and acting in relational ways that take into consideration how enviro-social determinants of health are key in shaping social and health policy (Bourque Bearskin, Kennedy, Kelly, \& Chakanyuka, 2020).

Nursing's caring activism means taking a stand and speaking up against racist and discriminatory interactions that extend far beyond what Joyce, Brian, and Silatik endured. It is about neutralizing power relations and systemic structures that forced Silatik to travel south to give birth alone and then die after contracting COVID-19. It is about recognizing trauma and violence as the backdrop to all potential health interactions. Reconciliation is more than just learning about the local communities, the local languages, or the names of community lands where you live. It means reconciling your own relationship with Indigenous Peoples' rights as a means of unsettling, disrupting, and provoking what we take for granted in the pursuit of human health rights and equity for and by Indigenous Peoples. While we have all been impacted by collective colonialism, the suffering has been endured by Indigenous Peoples who are being excluded, silenced, marginalized, and left isolated. We must heed the growing calls for decolonial love and activism in health care that is needed to advance Nation-to-Nation relationships and collective healing. In addition to the actions we outline here, we also invite you to join a growing team of Indigenous and non-Indigenous scholars who are advocating for antiracism to become one of the main pillars of the Canada Health Act. Are you ready to take action?

\section{Breaking the Conspiracy of Silence on Racism by Haida Nation}

Lauren Brown and Monica Brown, Haida Nation Health Directors, make visible the pervasiveness of racism in health care as part of the colonial experience, and share strategies to 
address it by engaging in more honest and direct dialogue and partnership from a rights-based framework.

Haida Kil Ad Giinaa'ah. Haida language and cultural ways of being have been impacted by colonialism since first contact. The colonial policies of the British North America Act of 1867 (now the Constitution Act, 1867) and the Indian Act continue to suppress and oppress our First Nations people through strict and stringent policies and systemic structures that do not align with our values and beliefs. As community health directors, we are often on the receiving end of complaints of poor treatment of our people within the health care system. Years of advocating for the fair and equitable treatment of our people have landed us in a place where no one takes responsibility for or control of the broken system we find ourselves in. The Farlex Dictionary of Idioms defines "conspiracy of silence" as "an agreement, either explicit or unspoken, among members of a group to keep secret certain information that, if exposed, could be damaging to the group, its interests, or its associates" (Farlex Inc., 2015). We have tried unsuccessfully to be meaningful and respected partners in the planning and implementation of health programs for our People. Our experience has been that we are engaged with meaningfully some of the time and not at all most of the time. Further, our attempts to shift the structures in place to support equitable and fair health care opportunities have been met with resistance and mistrust that further perpetuate the racist ideologies that we are "troublemakers."

The impacts of racism in the health care system on our people not only include poor health outcomes but also feelings of shame and inadequacy, of being "less than." We have suffered the continued invalidation and lack of acknowledgement of our history and determinants of our health, leading to many of our people feeling that "nobody could really understand," and thus contributing to the "conspiracy of silence." This intended and unintended consequence of ill health is directly related to our people not feeling safe to interact with health care professionals in health care settings, including community clinics and hospitals. When and how we talk about race in service provision and experience is often dictated by the "politeness protocol," whose ground rule states that potentially offensive or uncomfortable topics should be a) avoided, ignored, and silenced; or b) spoken about in a very light, casual, and superficial manner. Addressing topics of race, racism, Whiteness, and white privilege are discouraged in favour of friendly and noncontroversial topics. All of these actions contribute to the problem never being fully addressed, and, of course, this directly impacts individual First Nations Peoples' right to receive care in a culturally safe way.

The health care system is set up with bureaucratic structures that seem impossible to penetrate. Our experience working with the health care system has been frustrating, demeaning, and culturally unsafe. Sue (2016) refers to five ineffective strategies used when addressing racism: 1) "do nothing"; 2) "sidetrack the conversation"; 3) "appease the participants"; 4) terminate the discussion; and 5) "become defensive" (pp. 230-234). All five of these ineffective strategies have been used and contribute to the problem of racism that is never fully addressed in a culturally safe way for our people. The report In Plain Sight, commissioned by the BC Ministry 
of Health (2020), confirms that a lack of accountability by leadership to stop the discriminatory behaviour contributes to racism in health care for our First Nations people.

We recommend that the province of $\mathrm{BC}$ review its policies to address its obligations under the United Nations Declaration on the Rights of Indigenous Peoples (2007), the Truth and Reconciliation Commission of Canada (TRC) Calls to Action (TRC, 2015), and the report of the National Inquiry into Missing and Murdered Indigenous Women and Girls (2019). We are simply seeking equitable funding, services, and treatment for our First Nations people, like what is available for other citizens of this province. We seek true partnerships that recognize and align with our rights as Indigenous and sovereign Peoples. We share this with respect and as the Health Directors of Haida Gwaii. Gum yan asing Kaangas giidaay han hll guudang gas ga. I will never again feel that I am less than.

\section{Collectively Moving Systemic Change Forward}

Our communities, families, and loved ones deserve care that is not only free of racism, but is also reflective of their culture and the values and expectations of being treated compassionately and respectfully, and to a high standard of care. This is not the reality of Indigenous Peoples' health care experiences in Canada. Racism and harm are daily occurrences for Indigenous people who are attempting to access health treatments, and while high-profile cases garner attention for a time, most cases go undocumented and unreported, escaping accountability and culpability. There is a great deal of dialogue about "closing the gap" in health status between Indigenous people and the general population; this cannot happen until antiIndigenous racism is eliminated. Indigenous people often do not access the health system because they fear how they will be treated, and when they do, they are not receiving the standard of care expected by most Canadians. This urgently needs to change for health status to improve and to be in alignment with the many declarations of commitments made to human rights and cultural safety.

Racial injustices can no longer be normalized. All Canadians must confront the systemic exclusion of Indigenous Peoples (Phillips-Beck et al., 2020). Racism is, and needs to be viewed by all in the health care system as, a key determinant of First Nations, Métis, and Inuit health. Training of Indigenous health care professionals in culturally safe and racism-free environments, and their placement with Indigenous populations, must be a priority. Accreditation, professional regulation, and quality standards must have zero tolerance for racism and discrimination.

Reconciliation is clearly not just an exercise in feel-good aspirations; it will require individual, collective, and systemic change, as well as the sharing of power. Anything less will maintain the unacceptable status quo of the loss of quality and life of Indigenous Peoples. True partnerships based in respect, reciprocity, and accountability are needed to co-create health services that meet Canadian and Indigenous standards, enable health and healing, and ensure zero tolerance for racism against First Nations and Indigenous peoples. What Kétéskwēw puts before us are the origins of her own Cree knowledge. Herein, we will find solutions by including the spirit, rights, equity, and humanness inherent in our cultural knowledge systems across Nations to our health 
care services. We anticipate the time when racism is dismantled across systems, bringing new possibilities and realizing the health and wellness of Indigenous Peoples.

\section{References}

BC Ministry of Health. (2020). In plain sight: Addressing Indigenous-specific racism and discrimination in B.C. health care. https://engage.gov.bc.ca/app/uploads/sites/613/2020/11/In-Plain-Sight-SummaryReport.pdf

Bourque Bearskin, R. L., Kennedy, A., \& Joseph, C. (2020). Bearing witness to Indigenous health nursing. Editorial. Witness: The Canadian Journal of Critical Nursing Discourse, 2(1), 1-8. https://doi.org/10.25071/2291-5796.70 https://witness.journals.yorku.ca/index.php/default/article/download/70/35/

Bourque Bearskin, R. L., Kennedy, A., Kelly, L. P., Chakanyuka, C. (2020). Indigenist nursing: Caring keeps us close to the source. In M., Hills, J., Watson, \& C. Cara (Eds.), Creating a caring science curriculum: An emancipatory pedagogy for nursing (2nd ed., pp. 249270). New York: Springer. https://doi.org/10.1891/9780826136039.0016

Canadian Association of Schools of Nursing. (2020). Framework of strategies for nursing education to respond to the calls to action of Canada's Truth and Reconciliation Commission. https://www.casn.ca/wp-content/uploads/2020/11/EN-TRC-RESPONSESTRATEGIES-FOR-NURSING-EDUCATIONTRC-Discussion-Paper-RevisedFinal.pdf

Farlex Inc. (2015). Conspiracy of silence. In Farlex Dictionary of Idioms. https://idioms.thefreedictionary.com/conspiracy+of+silence

National Inquiry into Missing and Murdered Indigenous Women and Girls. (2019). Reclaiming power and place: The final report of the National Inquiry into Missing and Murdered Indigenous Women and Girls. https://www.mmiwg-ffada.ca/final-report/

Phillips-Beck, W., Eni, R., Lavoie, J. G., Avery Kinew, K., Kyoon Achan, G., and Katz, A. (2020). Confronting racism within the Canadian healthcare system: Systemic exclusion of First Nations from quality and consistent care. International Journal of Environment Research in Public Health, 17(22), 8343. https://doi.org/10.3390/ijerph17228343

Sue, D. W. (2016). Race talk and the conspiracy of silence: Understanding and facilitating difficult dialogues on race. John Wiley \& Sons Inc.

Symenuk, P. M., Tisdale, D., Bourque Bearskin, D. H., \& Munro, T. (2020). In search of the truth: Uncovering nursing's involvement in colonial harms and assimilative policies five years post Truth and Reconciliation Commission. Witness: The Canadian Journal of Critical Nursing Discourse, 2(1), 84-96. https://doi.org/10.25071/2291-5796.51

Thorne, S. (2019). Genocide by a million paper cuts. Editorial. Nursing Inquiry, 26(3). https://doi.org/10.1111/nin.12314

Truth and Reconciliation Commission of Canada. (2015). Honouring the truth, reconciling for the future: Summary of the final report of the Truth and Reconciliation Commission of Canada. 
http://www.trc.ca/assets/pdf/Honouring_the_Truth_Reconciling_for_the_Future_July_23 _2015.pdf

United Nations Declaration on the Rights of Indigenous Peoples, September 13, 2007, https://www.un.org/development/desa/indigenouspeoples/declaration-on-the-rights-ofindigenous-peoples.html 